\title{
Research on the Development of Shaoxing Health Care Industry under the Background of Digital Economy
}

$\mathrm{Yi} \mathrm{Xu}$

Zhejiang Yuexiu University, Shaoxing 312000, Zhejiang Province, China

Abstract: In recent years, China's economy has developed rapidly and people's lives have generally improved, but there are also many problems accompanying it. The life pressure of the population is high, the rural population is migrating to cities to work, and there are many left-behind elderly in the rural areas; aging is increasing, and the retirement age in cities continues to shift. As the problem of aging in our country becomes increasingly prominent, the need to build a digital health care industry is becoming more urgent. At present, the current situation of health care in our country is problematic. In this regard, we should face up to the problems existing in the current traditional health care model, and actively introduce "Internet + " to create a digital health care industry. Through changing thinking and strengthening management, it can provide the elderly with more accurate. At the same time, the service of the elderly can also shorten the distance between the elderly and the society, and truly achieve "the elderly have a sense of support" at the same time.

Key words: Digital economy; Health care industry; Development research

Publication date: December, 2020

Publication online: 31 December, 2020

"Corresponding author: Yi Xu, 40990744@qq.com

\section{Introduction}

China is not only a country with a large population, but at this stage the number of elderly people in China is huge, and the phenomenon of population aging is increasing, which has brought certain problems to China's security system. In order to ensure the balance and perfection of China's social system, the health care industry has become one of the rapidly developing industries in China. The government should attach importance to the health care industry and raise the health care industry to a strategic height. The transformation of the current health care industry model and the use of the "digital economy" to develop the health care industry is not only an important measure to improve the level of China's elderly care services, but also an important window to reflect the image of the Chinese government. With the continuous development and improvement of current Internet information technology, the use of the "digital economy" to develop the health care industry is the only way for the improvement and development of China's social security system, and it is also an important window to reflect the innovative service management methods of the Chinese government. In the process of policy implementation, the government should take the initiative to assume the main role in strategic measures such as system construction, facility construction, and soft environment transformation. The digital health care industry has changed the traditional integrated and modularized services of elderly care services. It is no longer a single service in the past, but a multi-level service. It provides service care from different angles, not only the traditional mode of life care, In medical and health care, cultural entertainment, information consultation and other service items have also been added. Compared with the traditional healthcare industry, the digital healthcare industry not only provides convenient and efficient services for the elderly, but also improves the service capabilities and service levels of the healthcare industry. Especially in terms of medical care, it provides more convenient, 
fast and accurate services for the elderly, which not only improves the quality of life of the elderly, but also guarantees the health of the elderly. The development of the "digital economy" health care industry is of great significance to the lives of the elderly.

\section{Development status of health care indu- stry in Shaoxing}

\subsection{Changing trend of population age structure}

As of the end of 2019, there were about 118,000 elderly people over 60 in Shaoxing, accounting for 13.35 percent of the total population. Compared with the previous year, 530 people increased, an increase of $0.46 \%$. Experts predict that by 2036 , the population over 60 years old in Shaoxing will reach
300,000 , and the population over 80 years old will also increase to 50,000 . At that time, the population aging will be more serious.

From 2009 to 2019, the proportion of elderly people over 60 in Shaoxing City increased from $9.52 \%$ to $13.35 \%$, an increase of $4.02 \%$. At this growth rate, the demand market for the elderly in Shaoxing will be very strong in the next ten years. In the next few years, Shaoxing City will usher in the "Silver Hair Era".

\subsection{Analysis of the situation of the elderly over 85}

According to statistics from the Office of Aging in Shaoxing City, as of December 31, 2019, there were 5,975 elderly people in Shaoxing City who were 85 years old and above. The basic situation is shown in the following table:

Table 1. The basic situation of the 85-year-old in Shaoxing

\begin{tabular}{|c|c|c|c|c|c|c|}
\hline & \multicolumn{2}{|c|}{ Gender } & \multicolumn{2}{|c|}{ Household registration } & \multicolumn{2}{|c|}{ Nationality } \\
\hline & female & male & Urbanarea & Ruralarea & Hannationality & minority \\
\hline Number of people (person) & 3614 & 2361 & 3112 & 2863 & 5138 & 837 \\
\hline Proportion (\%) & 60.5 & 39.5 & 52.1 & 47.9 & 86.0 & 14.0 \\
\hline
\end{tabular}

Table 2. Distribution of the basic situation of 85-year-olds in Shaoxing

\begin{tabular}{|c|c|c|c|c|c|c|}
\hline & \multicolumn{2}{|c|}{ Cultural status } & \multicolumn{2}{|c|}{ Health status } & \multicolumn{2}{|c|}{ Rehabilitation form } \\
\hline & $\begin{array}{l}\text { Illiterate and } \\
\text { semi-literate }\end{array}$ & Others & $\begin{array}{c}\text { Basically take care } \\
\text { of themselves }\end{array}$ & $\begin{array}{c}\text { Cannot take care } \\
\text { of themselves }\end{array}$ & Live with children & Others \\
\hline Number of people (person) & 4963 & 1012 & 3926 & 2049 & 5105 & 870 \\
\hline Proportion $(\%)$ & 83.1 & 16.9 & 65.7 & 34.3 & 85.5 & 14.5 \\
\hline
\end{tabular}

It can be seen from Table 1 and Table 2 that the proportion of women over the age of 85 in Shaoxing is higher than that of men, with a difference of $21 \%$; from a cultural perspective, illiterate and semiilliterate account for the majority, accounting for $83.1 \%$. Educational levels are generally low; $85.5 \%$ of people choose to live at home with their children. At the same time, families with an aging population are still growing, and living with their children and grandchildren is their first choice.

\subsection{Analysis of the status quo of urban and rural per capita income}

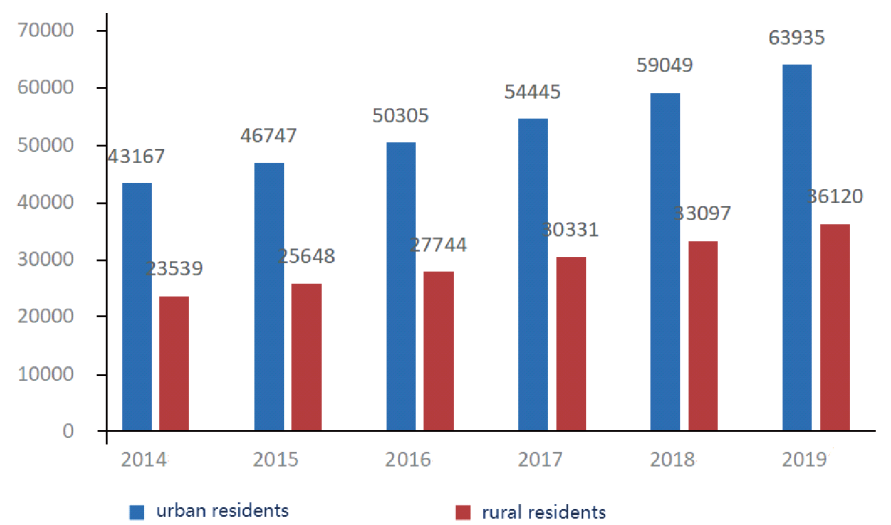

Figure 1. Per capita disposable income of urban and rural residents in Shaoxing from 2014 to 2019 
It can be seen from Figure 1 that from 2014 to 2019, the per capita income of urban and rural residents increased year by year, but the per capita income of urban and rural residents differed greatly. Specifically, the per capita disposable income of urban residents is about twice that of rural residents.

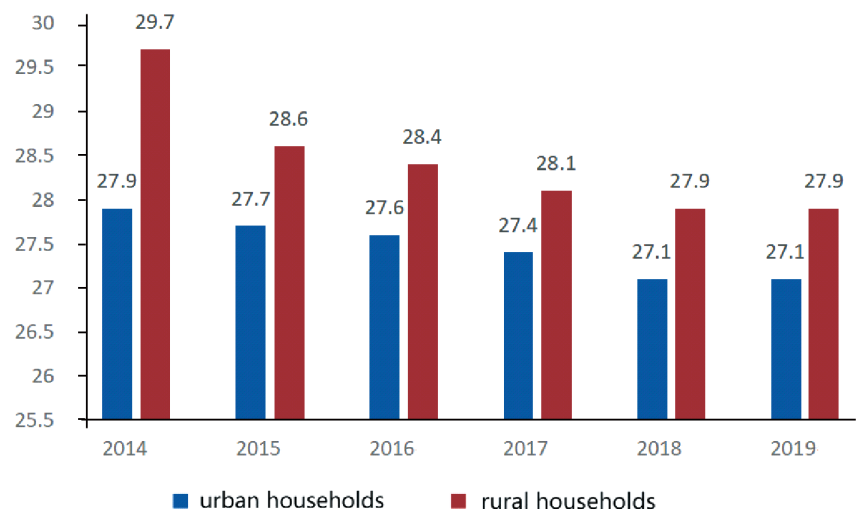

Figure 2. The Engel Coefficient of Urban and Rural Households in Shaoxing from 2014 to 2019

It can be seen from Figure 2 that the Engel coefficient of urban households has not changed much from 2014 to 2015, and they are relatively rich. However, from 2014 to 2019, the Engel coefficient showed a downward trend year by year, and the living standards of residents gradually improved from food and clothing to a relatively comfortable life. Generally speaking, if the Engel coefficient of rural residents gradually narrows the income gap of urban residents, their living standards will improve. The elderly will pay more attention to the choice of health care model than ever before, and the wealthy elderly will also pay more attention to health care. The quality and service requirements of health care services are getting higher and higher, and the demand for professional health care models is also increasing.

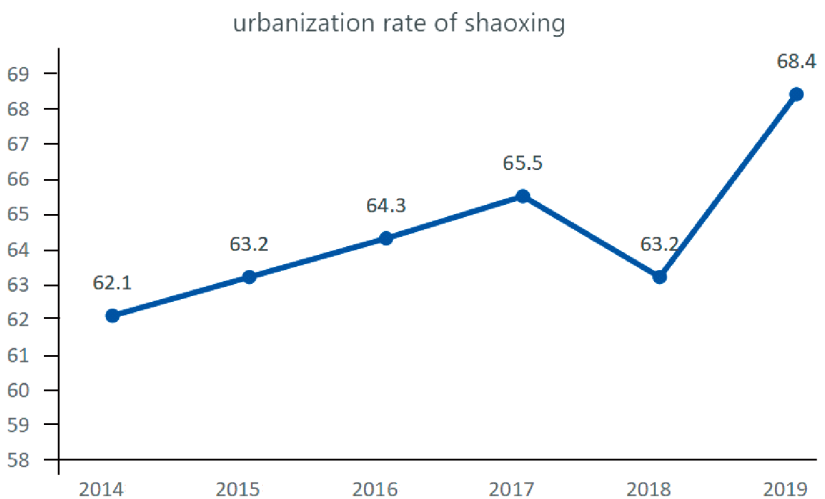

Figure 3. Changes in the urbanization rate of Shaoxing from 2014 to 2019

It can be seen from Figure 3 that from 2014 to 2019 , the urbanization rate of Shaoxing City has increased by nearly $6 \%$. Currently, the urban population accounts for $68.4 \%$ of the total population. This means that more and more rural people will enter cities and adopt urban lifestyles, including the elderly in rural areas, to receive health care services in the urban market, which will inevitably promote the growth of demand for the health care service industry .

\subsection{Analysis of personalized needs for health and wellness}

Although about half of the elderly in Shaoxing choose to live with their children, their needs for various services are still different. According to the survey, $90 \%$ of the elderly need people to provide various services. Among them, the top three are health care, physical exercise and life care. With changes in the social environment and advances in science and technology, the needs of the elderly have also undergone qualitative changes. Compared with the needs of old people in the past, modern old 
people pay more attention to their physical fitness. They have rich life experience, knowledge and skills, and have a healthy body. Therefore, the needs of the elderly have shifted from elderly life to high-quality elderly care. In particular, the needs of the elderly in the past were the guarantee of material life, such as traditional solutions to food, clothing, housing, and travel problems, while modern elderly people have put more and more demands on support, medical care, and family spirit on the basis of ensuring material life. The higher the requirements.

\section{Problems in the development of health care industry in Shaoxing}

\subsection{Lack of supply and demand information communication mechanism}

At present, the main health care model in Shaoxing City is home health care. This traditional health care model has many problems and limitations. The community provides services for the elderly by integrating families and social service elderly care institutions. However, such a model often does not correspond to demand and supply. When the elderly put forward demands to the community, they often need to pass more steps. The community collects information, screens information, and arranges services. This model is not only problematic in this respect. The most important thing is the inability to communicate. The elderly cannot communicate with the platform and the final service personnel. The mismatched communication leads to a mismatch in demand, and the mismatch in demand ultimately results in a lot of serious waste of resources prevents many services from being effectively carried out. The convenience and flexibility of information communication for the elderly are insufficient, the communication barriers between the supply and demand sides are serious, and the supply and demand information communication mechanism is lacking.

\subsection{Relatively single service}

\subsubsection{Single service content}

The existing traditional home care services are not complete in content, and the targeted services are relatively narrow. Such services have not received comprehensive care for the lives of the elderly. Community elderly care and civilian nutrition institutions are now the main providers of elderly care services. The main service content of the organization is only concentrated in the material aspects of life, such as: food delivery, laundry, cleaning and other daily services. Lack of care for the physical and mental health of the elderly. The service content is relatively single.

\subsubsection{Single service method}

The existing health care in Shaoxing City is based on housekeeping and nanny service as the main service method. It is relatively simple, untargeted, and has a single service method, ignoring the real needs of the elderly. The elderly have no sense of experience, and they are often served in a convenient way. The elderly can only passively accept poor quality and insufficiently innovative services

\subsubsection{Single form of service}

The existing health care in Shaoxing City is mainly home-based care. However, due to China's early national conditions and policies, coupled with current people's pressure, the size of families in our country is becoming smaller and smaller. Many families have a "4-2-1" structure. Under the circumstances, it is even more necessary to resort to community services and professional elderly care service agencies. The current forms of elderly care services are similar and too single. To a large extent, it cannot meet the needs of the elderly.

\subsection{There are certain security risks}

Medical treatment and emergency rescue are very important to us. Among the elderly, the importance of medical treatment and emergency rescue is self-evident. Because sudden abnormalities in the elderly are very common. Elderly people staying at home will seek help from the community as soon as they have abnormal health or emergencies, and the community will contact relevant medical institutions to provide medical assistance. After all these procedures are completed, the prime time for rescue may be lost, which greatly increases the risk to the life safety of the elderly. The existing health care industry cannot meet the required requirements in the all-weather monitoring of the elderly. It is difficult to respond quickly when an emergency occurs, which often delays the best treatment opportunity and poses a certain life safety risk. 


\section{The path choice for the development of Shaoxing's health care industry under the background of digital economy}

\subsection{Reasonable use of the "Internet +" platform}

First of all, we should be proficient in using Internet technology, combined with the current status of China's health care industry, reasonably and efficiently use the "Internet + " platform to provide convenient and diversified health care services for the elderly. Relevant government industry departments can launch real-time monitoring instruments, such as smart bracelets and smart elderly phones. Use Internet technology to aggregate and classify information and needs of the elderly. Information and needs are distributed to professionals in the community's professional teams through smart terminals. In addition, the platform's monitoring mode allows children who go out to pay attention to the lives and bodies of the elderly in real time, so that children who go out can rest assured. At the same time, after professional training or university education for the elderly, the elderly can use the Internet knowledge and operating skills they have learned to conduct consultations and customize health care services on the network platform according to their needs. The smart elderly care platform monitors the huge amount of information about the elderly, and integrates these related information to form a classified database. Then, the information and data integrated on the platform can be organized and dig deeper again, so that a relatively reliable solution can be provided. Based on the collected information, provide accurate medical services for the elderly. In an emergency, precise and efficient treatment can save the lives of the elderly. Through the application of Internet technology, real-time monitoring of the physical condition of the elderly is realized, which saves time, provides more accurate services, and narrows the distance between the elderly and their children.

\subsection{Creating personalized health care services}

We should not only pay attention to the elderly in our lives, but more importantly, we need to pay attention to the elderly spiritually so that they can feel respected. Give full play to the talents and skills of the psychological counseling profession in the professional service team of the health care industry, and regularly send the necessary care to the elderly.
Of course, we also need to organize entertainment and friendship activities for the elderly, so that the elderly can obtain activity information through the platform, and then participate spontaneously to promote communication among the elderly. Create a variety of activities to create a good atmosphere for mutual assistance and exchanges in smart elderly care services. At the same time, we can provide simple and basic nursing care training for young people who can take care of themselves and have independent social skills, so that they can participate in the care of the elderly. On the one hand, it alleviates the shortage of nursing staff in the health care industry, on the other hand, it makes the elderly who can't take time off to do something, and at the same time strengthens the communication between the elderly. Digital health care provides diversified and personalized services. Organize various activities and establish various facilities to meet the needs of elderly people at different levels.

\subsection{Systematizing to create smart health care}

The first thing to do is to conduct scientific analysis and research, and mobilize resources from all walks of life to conduct visits and surveys to the elderly. For the greatest degree of credibility and practicability of this survey, it is necessary not only to conduct research on the elderly, but also to the elderly. Relatives of people's children conduct research. After the survey results are summarized and classified, the needs of the elderly are extracted and then classified and classified. Through the research, we can know that we should pay more attention to the spiritual needs of the elderly in addition to the scheduled care of the elderly, and target the elderly at different levels. People, provide different spiritual needs, this level of health care services can be truly customized, and can truly "prescribe the right medicine". Second, optimize public resources. Through investigation and reading and research of the materials, we know that many health care industries in our country often have the problem of no available items. The limited space, fewer health care resources, and fewer professional service personnel are all reasons why no items are available. In this case, in order to achieve effective use of public resources, market-oriented, we should vigorously promote a new health care model. For example, what we call today the "G2C" team is for individuals, and a dedicated health care service 
professional team is established in the community. In addition to the needs of the elderly through the platform, some on-site services are provided for the elderly on a regular basis. While meeting the daily needs of the elderly, it can also reduce the pressure burden of the nursing home. After the centralized management of the community, the last mile of serving the elderly has been opened up, and the elderly who cannot live on their own are provided by professional agency personnel, so that the elderly can rest assured and the family members can rest assured. Finally, we also need to strengthen information technology education for the elderly. Because the new health care model needs to be operated through smart phones, computers and other intelligent terminals, we need to provide a full range of services and management according to the actual needs of the elderly, and provide personalized and diverse services. On the premise of understanding and respecting the elderly, we will carry out information technology education for the elderly and teach them according to the actual situation and needs of the elderly, so that the elderly can truly master information technology and use the Internet proficiently, crossing the silver gap.

\section{References}

[1] Zhou GY. Research on the Development Status and Countermeasures of Qingbaijiang Smart Health Care Industry [D]. Sichuan Agricultural University, 2018.

[2] Zheng Z. Research on the Optimal Development Strategy of the County Health Care Industry in the New Era: Based on the Analysis of the Top 100 Counties in Yidu City [C]. Jingchu Academic (July 2019). 2019.

[3] Huang JJ. Research on the development of county-level health care industry in the strategy of rural revitalization--Taking Yibin county, Sichuan province as an example [J]. Economist, 2020(12):147-148+150.

[4] Zhu Y. Research on the sustainable development of health industry in Henan province and countermeasures $[\mathrm{J}]$. Value Engineering, 2019(30):106-107.

[5] Chen F. Research on Panzhihua health care industry development from the perspective of supply-side reform[J]. Taxation, 2018(33):169-170. 